Résumés des conférences et travaux

\title{
Philologie italique
}

\section{Emmanuel Dupraz}

\section{(2) OpenEdition \\ Journals}

\section{Édition électronique}

URL : https://journals.openedition.org/ashp/4259

DOI : $10.4000 /$ ashp.4259

ISSN : 1969-6310

Éditeur

Publications de l'École Pratique des Hautes Études

\section{Édition imprimée}

Date de publication : 1 septembre 2021

Pagination : 147-149

ISSN : 0766-0677

\section{Référence électronique}

Emmanuel Dupraz, "Philologie italique », Annuaire de l'École pratique des hautes études (EPHE), Section des sciences historiques et philologiques [En ligne], 152 | 2021, mis en ligne le 14 juin 2021, consulté le 20 juin 2022. URL : http://journals.openedition.org/ashp/4259; DOI : https://doi.org/10.4000/ashp. 4259 


\title{
PHILOLOGIE ITALIQUE
}

\author{
Directeur d'études : M. Emmanuel DuPRAZ
}

Programme de l'année 2019-2020 : I. Contacts de langues dans l'Italie ancienne : le messapien et ses voisins. - II. Textes prescriptifs sabelliques : la loi de Bantia.

En 2019-2020, la conférence a comporté deux parties séparées, dont la deuxième a été très perturbée par les restrictions dues à l'épidémie de coronavirus.

Le premier thème discuté a été celui des contacts entre le messapien et les langues voisines, principalement l'osque et le grec. Le messapien est la langue d'environ sixcents inscriptions retrouvées dans la région des Pouilles au sud-est de l'Italie, et plus précisément, pour la grande majorité d'entre elles, dans la péninsule du Salento. Les documents datent d'entre le $\mathrm{VI}^{\mathrm{e}}$ et le $\mathrm{II}^{\mathrm{e}}$ siècle avant notre ère. Le messapien est sans aucun doute une langue indo-européenne, mais il est difficile de préciser sa place à l'intérieur de cette famille; la langue présente des traits qui semblent la rapprocher de langues des Balkans, notamment l'albanais, malheureusement attesté seulement à partir d'une date bien plus récente, et le grec.

La situation des études messapiennes est plus favorable qu'il y a plusieurs décennies, d'une part en raison de l'existence d'un corpus doté d'index utiles et de photographies, celui de de Simone et Marchesini (2002), d'autre part en raison de la parution toute récente d'une synthèse excellente qui présente l'ensemble des données linguistiques pouvant être considérées comme acquises, celle de Matzinger (2019). Il n'est pas exagéré de dire que cet ouvrage représente le point de départ d'une nouvelle phase dans l'étude du messapien, qui, parce qu'il n'appartient pas à la famille des langues italiques (latin, falisque, ombrien, picénien, osque), a été largement négligé dans les études sur l'épigraphie de la péninsule italienne.

Le séminaire a porté sur plusieurs séries de textes messapiens. Ont en particulier été analysés les textes longs du corpus messapien, qui, malheureusement, pour la plupart, sont connus seulement par des transcriptions datant des $\mathrm{XVI}^{\mathrm{e}}$ à $\mathrm{XIX}^{\mathrm{e}}$ siècle, les pierres étant perdues. L'étude de ces textes a permis d'émettre l'hypothèse qu'il s'agit de commémorations particulièrement solennelles d'actes effectués par plusieurs magistrats ou en tout cas sous la caution de nombreux magistrats ou en faisant appel à l'éponymie de nombreux magistrats. Ces textes peuvent contenir des prohibitions, probablement contre qui contreviendrait à l'ordre établi par l'acte commémoré. Ils sont souvent placés sous le patronage de deux divinités, zis, dont le nom correspond étymologiquement à celui de Zeus et de Jupiter, et venas, dont le nom est le pendant de celui de Vénus, attesté en latin et aussi en osque.

Ces inscriptions montrent que la Vénus messapienne n'a pas les mêmes fonctions que l'Aphrodite messapienne, qui est attestée elle aussi. En effet Aphrodite, divinité au nom emprunté au grec, dont les prêtresses sont des femmes et qui reçoit des 
dédicaces effectuées par des femmes, n'est certainement pas la même figure divine que Vénus, laquelle appartient à la sphère de Jupiter et est attestée comme ce dernier au début de commémorations d'actes divers, mais toujours solennels. La différence très nette, et sans exception, entre les genres de textes où est attesté le nom de venas et ceux où figure celui d'Aphrodite, exclut absolument qu'il puisse s'agir du nom indigène et du nom grec d'une seule et même divinité.

Le corpus messapien pose ainsi la question du statut de Vénus en osque et même en latin. En osque, Vénus est attestée directement par deux textes du sud, trouvés dans les dernières décennies dans des régions proches des aires de langue messapienne. Les implications de cette situation n'ont peut-être pas encore été tirées. Il n'est nullement certain que la Vénus osque ait les mêmes valences que la Vénus du latin classique, d'autant plus que l'osque présente aussi une divinité nommée herentas "Désir » qui paraît bien être le correspondant fonctionnel d'Aphrodite. Cette situation rappelle celle du messapien où Vénus est distincte d'Aphrodite, et laisse supposer que la Vénus osque, comme son homonyme messapienne, n'a rien à voir avec la sexualité, laissant la tutelle de celle-ci à herentas. En latin classique même, du coup, la question se pose à nouveaux frais de savoir pourquoi Vénus est à la fois la fille de Jupiter, mère d'Énée, tutélaire pour la cité de Rome, et par ailleurs une déesse de la sexualité liée à la notion de féminité.

Après cette étude du corpus messapien, destinée à se poursuivre dans les prochaines années, le séminaire s'est tourné vers le plus long document osque, la loi de Bantia. Ce texte étudié récemment de manière très convaincante par Cappelletti (2011) a été gravé à une date difficile à établir avec certitude, probablement au début du $\mathrm{I}^{\mathrm{er}}$ siècle avant notre ère, dans un site qui semble peu habité auparavant, et qui vient alors à peine de recevoir des institutions civiques. L'étude de ce texte, commencée au début du second quadrimestre de l'année académique, a continué malgré les restrictions dues au confinement.

Elle a porté sur le contexte archéologique de la loi, à savoir principalement l'auguraculum aménagé à Bantia probablement à une date proche de la gravure du texte. Il s'agit bien là, d'une manière qui nous semble sûre, d'un lieu aménagé pour des prises d'auspices régulières, comparable à celui qui est décrit dans la version longue du rituel de piaculum de Gubbio (Table Eugubine VI a, lignes 1 à 18). Cet aménagement n'est pas nécessairement lié à la fondation de Bantia comme organisme politique, puisqu'il s'agit d'un lieu d'usage régulier dans le fonctionnement courant de cet organisme. La comparaison entre la source textuelle ombrienne et la source archéologique osque est difficile et a donné lieu à des réflexions qui ont pris en compte aussi les textes littéraires latins décrivant les lieux de prise d'auspices romains. Nous escomptons reprendre à l'avenir cette comparaison qui nous paraît promettre une analyse plus satisfaisante du passage ombrien, l'un des plus complexes des Tables Eugubines.

Le séminaire, en raison des restrictions d'accès à la bibliographie dues au confinement, interdisant une étude détaillée du texte lui-même de la loi de Bantia, a examiné l'ensemble de ces documents liés aux prises d'auspices plus longuement qu'il n'était prévu. Le contenu normatif de la loi devra faire l'objet d'une analyse détaillée dans les années à venir. 


\section{Références bibliographiques}

Cappelletti (Loredana), Gli Statuti di Banzi e Taranto nella Magna Grecia del I secolo a.C., Francfort-sur-le-Main, 2011.

De Simone (Carlo) et Marchesini (Simona), Monumenta linguae Messapicae, Wiesbaden, 2002. Matzinger (Joachim), Messapisch, Wiesbaden, 2019. 